\title{
Treatment of a true CXA-OM bifurcation lesion using a one stent drug-coated balloons provisional technique
}

\section{DKrešimir Gabaldo*, (i)Božo Vujeva, DKatica Cvitkušić Lukenda, \\ DMarijana Knežević Praveček, Domagoj Vučić}

General Hospital „Dr. Josip Benčević" Slavonski Brod, Slavonski Brod, Croatia
RECEIVED:

February 11, 2020

ACCEPTED:

February 22, 2020

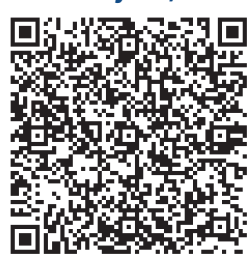

KEYWORDS: bifurcation lesions, acute coronary syndrome, drug coated balloons. CITATION: Cardiol Croat. 2020;15(3-4):51. | https://doi.org/10.15836/ccar2020.51

*ADDRESS FOR CORRESPONDENCE: Krešimir Gabaldo, Opća bolnica Dr Josip Benčević, A. Štampara 42, HR-35000 Slavonski Brod, Croatia. / Phone: +385-98-1398-810 / E-mail: kresimir.gabaldo@gmail.com

ORCID: Krešimir Gabaldo, https://orcid.org/0000-0002-0116-5929 • Božo Vujeva, https://orcid.org/0000-0003-0490-3832 Katica Cvitkušić Lukenda, https://orcid.org/0000-0001-6188-0708

Marijana Knežević Praveček, https://orcid.org/0000-0002-8727-7357

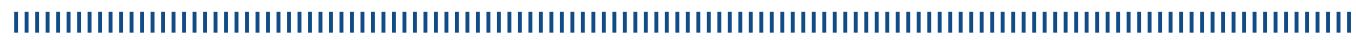

Background: Provisional stenting is a favorable option for most bifurcation lesions, while two stent techniques show benefits in true bifurcation performed by experts. Using one stent and DCB in true bifurcation lesions still remains questionable. ${ }^{1,2}$

Case report: 76-year-old male presented with persisting chest pain. ECG showed no specific ischemic changes, while hsTnI was highly elevated. He had gone PCI LAD 14 years ago. Diagnosis: right coronary angiography revealed occlusion of RCA, while left coronary angiography revealed LLS of $20 \%$ in proximal LAD stent, 70\% stenosis of mid LAD, and acute occlusion of secondary OM branch on bifurcation level, while CxA was stenosed 70-80\%. Management: PCI CXA-OM2 was performed with DES Xience expedition 2,75/33mm in CXA-OM2 with POT 3,25/12 mm proximally, then after rewiring and adequate lesion preparation a DEB Sequent please $2,5 / 25 \mathrm{~mm}$ in CXA distally was performed. After two months we performed an elective PCI LAD and checked out the result of CXA bifurcation which was optimal.

Conclusion: Using one stent and DCB in true bifurcation lesions still remains questionable. There are no data from a prospective study, while there are data from the observational study which enrolled 130 patients. DCB-only strategy was performed in 54\% patients, $34.6 \%$ had at least one stent in the main branch, $8.5 \%$ had at least one stent in the side branch and $3.1 \%$ at least one stent in the main branch and side branch. Study follow up lasted for 9.8 months. The TLR rate was 4.5\%, MACE was $6.1 \%$, and no stent thrombosis was detected. This study suggested that the DCB+one stent, and DCB-only strategy was safe and effective in selected bifurcations, possibly allowing for an abbreviated antiplatelet regimen.

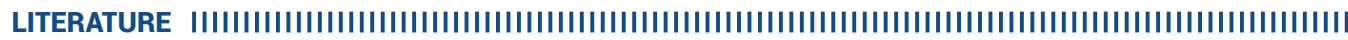

1. Bruch L, Zadura M, Waliszewski M, Platonic Z, Eränen J, Scheller B, et al. Results From the International Drug Coated Balloon Registry for the Treatment of Bifurcations. Can a Bifurcation Be Treated Without Stents? J Interv Cardiol. 2016 Aug;29(4):348-56. https://doi.org/10.1111/joic.12301

2. American College of Cardiology. The 15th Meeting of the European Bifurcation Club. Avaialble from:

https://www.acc.org/latest-in-cardiology/articles/2019/11/07/08/36/the-15th-meeting-of-the-european-bifurcation-club (February 10, 2020). 